\title{
The Changing Landscape of Treatment for Intracranial Aneurysm
}

\author{
Christopher S. Lozano (i), Andres M. Lozano, Julian Spears
}

\begin{abstract}
There has been a significant transformation in the treatment of intracranial aneurysms (IAs) over the past century, with the most pivotal changes occurring in the past three decades. To characterize this evolution, we assessed the number of articles published on various procedures for the treatment of IA as a measure of their interest and usage over time. We separated our analysis into two main areas: surgical and endovascular approaches. We further subdivided these two main categories into clipping and bypass for surgery, and coiling, flow diversion, and liquid material embolization for endovascular approaches. We found 5956 publications on open surgical approaches in the 70-year period from 1947 to 2017, with papers on clipping $(n=4204)$, being the most common. We found 8602 endovascular publications beginning in 1964, with most of the activity taking place in the late 1990s and beyond. Coiling had the most publications of the endovascular approaches $(n=5436)$. In 1999 , the number of annual publications on endovascular treatments surpassed those of open surgery, signaling a crossover point in the IA literature. The same trend continues to this date.
\end{abstract}

RÉSUMÉ : Comment les traitements des anévrismes intracrâniens se sont diversifiés au fil du temps. Depuis un siècle, particulièrement au cours des trois dernières décennies, des transformations notables sont survenues en ce qui regarde le traitement des anévrismes intracrâniens (AI). Afin de caractériser cette évolution, nous avons tenté d'évaluer le nombre d'articles publiés au sujet des diverses approches visant à traiter les AI. Cela nous a permis de mesurer l'intérêt à l'égard de ces approches ainsi que leur fréquence d'utilisation au fil du temps. Nous avons divisé ainsi notre analyse en deux volets : l'approche chirurgicale et celle de nature endovasculaire. La première approche a été ensuite subdivisée en deux techniques, soit le clipping et le pontage, tandis que la seconde a été subdivisée en trois techniques distinctes : la pose de spires métalliques (ou coiling), la dérivation de l'écoulement et l'embolisation liquide à l'aide d'implants. Nous avons ainsi répertorié 5956 publications portant sur une approche chirurgicale ouverte au cours de la période allant de 1947 à 2017, les articles abordant la technique du clipping étant les plus courants $(n=4204)$. Nous avons par ailleurs répertorié 8602 articles consacrés aux techniques endovasculaires, et ce, à partir de 1964. À noter que la plupart de ces articles ont été publiés à la fin des années 90 et au courant des années 2000 et 2010. Parmi toutes les techniques endovasculaires, c'est la pose de spires métalliques qui a fait l'objet du plus grand nombre de publications $(n=5436)$. Il est aussi bon de rappeler que c'est en 1999 que le nombre de publications annuelles portant sur les techniques endovasculaires a fini par dépasser celui des publications mettant l'accent sur l'approche chirurgicale, ce qui indique un point de bascule dans la littérature scientifique abordant la question des AI. Cette tendance demeure inchangée jusqu'à aujourd'hui.

Keywords: Intracranial aneurysm, Clipping, Coiling, Flow diversion, Extra-cranial to intracranial bypass doi:10.1017/cjn.2019.7

Can J Neurol Sci. 2019; 46: 159-165

\section{INTRODUCTION}

Aneurysms are thought to have first been described more than 2000 years ago in Egyptian antiquity. ${ }^{1}$ For much of their history, aneurysms, especially intracranial aneurysms (IAs), have been poorly understood and had limited treatment options. Proximal ligation of the cartotid artery was the first mainstream surgery for IA used by pioneers like Cooper in the 1800s to variable success. ${ }^{2,3}$ Over the years, gradual improvements were made to the proximal ligation method although it was still held back by a high risk of complications. ${ }^{4}$ Modern surgery for IA can be described in four periods: the Pre-Microsurgical era (pre-1960); the Early Microsurgical era (1960-1980); the Late Microsurgical era (1980-2000); and the Continuing Innovations era (2000present). ${ }^{5}$ The predominant treatment for IA during each of these periods was defined by their contemporary technology.

Surgical approaches for IA dominated the Pre-Microsurgical and Early Microsurgical eras. Clipping of IAs was introduced in the early 1930s and soon became the standard approach. Throughout the mid-to-late 20th century, clipping benefited from a number of innovations such as improvements in clip design, diagnostic imaging, and the introduction of the surgical microscope. For many years, clipping was regarded as the definitive treatment for IAs; however in the Late Microsurgical era (19802000) and the Continuing Innovations era (2000-present), the advent of endovascular approaches emerged. These minimally invasive procedures could avoid some of the adverse effects of open surgery while being capable of producing good results. ${ }^{6}$

From the Department of Surgery, Division of Neurosurgery, University of Toronto, Toronto, Ontario, Canada (CSL, AML, JS)

Received October 1, 2018. Final Revisions Submitted December 20, 2018. Date of ACCEPTANCE January 14, 2019.

Correspondence to: Christopher Lozano, St. Michael's Hospital, 30 Bond Street, Toronto, Ontario, Canada. Email: christopherlozano@rcsi.com 
Table 1: Summary of publications on the treatment of intracranial aneurysms. The numbers represent publications cataloged in Scopus up to 2017. Search terms used are provided in the table footnote

\begin{tabular}{|c|c|c|c|c|}
\hline Topic & $\begin{array}{c}\text { Total number of } \\
\text { publications }\end{array}$ & $\begin{array}{c}\text { Year of earliest } \\
\text { publication }\end{array}$ & $\begin{array}{l}\text { Maximum number of } \\
\text { annual publications }\end{array}$ & $\begin{array}{c}\text { Year of maximum } \\
\text { number of publications }\end{array}$ \\
\hline IA treatment ${ }^{\mathrm{a}}$ & 21,255 & 1938 & 1241 & 2016 \\
\hline Surgical approaches (generic) ${ }^{\mathrm{b}}$ & 5956 & 1947 & 299 & 2015 \\
\hline Clipping $^{\mathrm{c}}$ & 4204 & 1947 & 294 & 2015 \\
\hline EC-IC bypass ${ }^{\mathrm{d}}$ & 23 & 1980 & 3 & 2011 \\
\hline IC-IC bypass ${ }^{e}$ & 15 & 2004 & 3 & 2014 \\
\hline Endovascular approaches (generic) ${ }^{\mathrm{f}}$ & 8602 & 1964 & 688 & 2016 \\
\hline Coiling $^{g}$ & 5436 & 1985 & 239 & 2014 \\
\hline Balloon-assisted coiling ${ }^{\mathrm{h}}$ & 80 & 2001 & 14 & 2016 \\
\hline Stent-assisted coiling $^{\mathrm{i}}$ & 522 & 2000 & 79 & 2016 \\
\hline Flow diversion ${ }^{\mathrm{j}}$ & 380 & 2004 & 90 & 2017 \\
\hline Liquid embolization $^{\mathrm{k}}$ & 30 & 1992 & 5 & 2014 \\
\hline
\end{tabular}

${ }^{a}$ TITLE-ABS-KEY (intracranial OR cerebral AND aneurysm) AND TITLE-ABS-KEY (surgery OR repair OR treatment) AND DOCTYPE (ar OR re). ${ }^{b}$ TITLE-ABS-KEY (Intracranial OR cerebral AND aneurysm) AND TITLE-ABS-KEY (craniotomy OR endoscopic OR clip OR bypass) AND NOT KEY (endovascular OR transluminal) AND DOCTYPE(ar OR re).

${ }^{\mathrm{c}}$ TITLE-ABS-KEY (Intracranial OR cerebral AND aneurysm) AND TITLE-ABS-KEY (endovascular OR transluminal OR coil OR embolization OR embolisation) AND NOT KEY (clip OR bypass) AND DOCTYPE (ar OR re).

dTITLE-ABS-KEY (intracranial OR cerebral AND aneurysm) AND TITLE-ABS-KEY ("Extracranial-to-intracranial” or "EC-IC" AND bypass) AND DOCTYPE (ar OR re).

'TITLE-ABS-KEY (intracranial OR cerebral AND aneurysm) AND TITLE-ABS-KEY (“intracranial-to-intracranial” OR "IC-IC” AND bypass) AND DOCTYPE(ar OR re).

${ }^{\mathrm{f}}$ TITLE-ABS-KEY (Intracranial OR cerebral AND aneurysm) AND TITLE-ABS-KEY (endovascular OR transluminal OR coil OR embolization OR embolisation) AND NOT KEY (clip OR bypass) AND DOCTYPE (ar OR re).

${ }^{\mathrm{g}}$ TITLE-ABS-KEY (Intracranial OR cerebral AND aneurysm) AND TITLE-ABS-KEY (coil OR coiling AND (endovascular OR embolization OR embolisation OR repair) AND DOCTYPE (ar OR re).

${ }^{\mathrm{h}}$ TITLE-ABS-KEY (intracranial OR cerebral AND aneurysm) AND TITLE-ABS-KEY ("balloon-assisted coiling”) AND DOCTYPE (ar OR re). ${ }^{i}$ TITLE-ABS-KEY (intracranial OR cerebral AND aneurysm) AND TITLE-ABS-KEY ("Stent-Assisted Coiling”) AND DOCTYPE (ar OR re). ${ }^{j}$ TITLE-ABS-KEY (intracranial OR cerebral AND aneurysm) AND TITLE-ABS-KEY ("Flow Diversion") AND DOCTYPE(ar OR re).

${ }^{k}$ TITLE-ABS-KEY (intracranial OR cerebral AND aneurysm) AND TITLE-ABS-KEY ("liquid embolization" OR "liquid embolisation" OR "liquid embolic material") AND DOCTYPE (ar OR re).

Various methods were tried over the years but the introduction of the detachable coil by Guglielmi in $1991^{7}$ is arguably the most important tool used in endovascular approaches to date. Since the 1990s, detachable coils have continued to evolve to the benefit of patient safety and reductions in cost. ${ }^{8}$ There has also been the introduction of novel endovascular technologies including flow-diverting stents and liquid embolization materials which are currently under active development.

It is evident that the landscape of treatment for IAs has changed dramatically over the past 100 years, especially during the 1990s. The purpose of the present study is to compile and analyze publications to appraise how academic interest in various procedures has changed with improvements in technology over time. The number of publications in various topics will be used as a proxy measure of this academic interest.

\section{MethodS}

We performed a generic search for all publications related to the treatment of IAs. We then compiled a list of keywords related to both surgical and endovascular repair of IAs. Based on these keywords, we performed a series of searches to find publications within these specific subtopics. The surgery keywords we used included aneurysm clipping, extracranial-tointracranial (EC-IC) bypass, and intracranial-to-intracranial (IC-IC) bypass. Endovascular keywords included aneurysm coiling, balloon-assisted coiling, stent-assisted coiling, flow diversion, and liquid material embolization. These terms were combined with the terms intracranial or cerebral aneurysm (exact search strings can be found in Table 1 footnotes). Our searches identified articles that contained these phrases within their titles, abstracts, or keywords.

Searches were performed in June and July 2018 using the Scopus database (www.scopus.com). The publications found were restricted to articles or reviews in scholarly journals. Articles published up until December 31st, 2017, were included in our analysis. The search results returned included the article name, author list, year published, and number of citations. This information was extracted into a spreadsheet which was screened for duplicate entries. The number of publications in each topic was tallied by year and displayed in graphical form. 
Table 2: The most highly cited publications on cerebral aneurysm treatment derived from Scopus up to 2017. Papers with over 400 citations (citation classics) are listed

\begin{tabular}{|c|c|c|c|c|c|}
\hline Rank & Authors & Year & Title & Topic area(s) & Number of citations \\
\hline 1 & Molyneux A. et al. & 2002 & $\begin{array}{l}\text { International Subarachnoid Aneurysm Trial (ISAT) of neurosurgical } \\
\text { clipping versus endovascular coiling in } 2143 \text { patients with ruptured } \\
\text { intracranial aneurysms: A randomised trial }\end{array}$ & Surgical + endovascular & 2217 \\
\hline 2 & Hunt W.E. et al. & 1968 & $\begin{array}{l}\text { Surgical risk as related to time of intervention in the repair of intracranial } \\
\text { aneurysms. }\end{array}$ & Surgical & 1970 \\
\hline 3 & Wiebers D.O. et al. & 2003 & $\begin{array}{l}\text { Unruptured intracranial aneurysms: Natural history, clinical outcome, and } \\
\text { risks of surgical and endovascular treatment }\end{array}$ & Surgical + endovascular & 1856 \\
\hline 4 & Molyneux A.J. at al. & 2005 & $\begin{array}{l}\text { International Subarachnoid Aneurysm Trial (ISAT) of neurosurgical } \\
\text { clipping versus endovascular coiling in } 2143 \text { patients with ruptured } \\
\text { intracranial aneurysms: A randomised comparison of effects on survival, } \\
\text { dependency, seizures, rebleeding, subgroups, and aneurysm occlusion }\end{array}$ & Surgical + endovascular & 1368 \\
\hline 5 & Wiebers D.O. et al. & 1998 & $\begin{array}{l}\text { Unruptured intracranial aneurysms - Risk of rupture and risks of surgical } \\
\text { intervention }\end{array}$ & Surgical & 1217 \\
\hline 6 & Raymond J. et al. & 2003 & $\begin{array}{l}\text { Long-term angiographic recurrences after selective endovascular treatment } \\
\text { of aneurysms with detachable coils }\end{array}$ & Endovascular & 918 \\
\hline 7 & Connolly E.S. et al. & 2012 & $\begin{array}{l}\text { Guidelines for the management of aneurysmal subarachnoid hemorrhage: A } \\
\text { guideline for healthcare professionals from the American Heart } \\
\text { Association/American Stroke Association }\end{array}$ & Surgical + endovascular & 914 \\
\hline 8 & Bederson J.B. et al. & 2009 & $\begin{array}{l}\text { Guidelines for the management of aneurysmal subarachnoid hemorrhage: A } \\
\text { statement for healthcare professionals from a special writing group of the } \\
\text { stroke council, American Heart Association }\end{array}$ & Surgical + endovascular & 893 \\
\hline 9 & Van Gijn J. et al. & 2001 & Subarachnoid haemorrhage: Diagnosis, causes and management & Surgical + endovascular & 789 \\
\hline 10 & Viñuela $F$. et al. & 1997 & $\begin{array}{l}\text { Guglielmi detachable coil embolization of acute intracranial aneurysm: } \\
\text { Perioperative anatomical and clinical outcome in } 403 \text { patients }\end{array}$ & Endovascular & 732 \\
\hline 11 & Kassell N.F. et al. & 1990 & $\begin{array}{l}\text { The International Cooperative Study on the Timing of Aneurysm Surgery. } \\
\text { Part 2: Surgical results }\end{array}$ & Surgical & 675 \\
\hline 12 & Pickard J.D. et al. & 1989 & $\begin{array}{l}\text { Effect of oral nimodipine on cerebral infarction and outcome after } \\
\text { subarachnoid haemorrhage: British aneurysm nimodipine trial }\end{array}$ & Medical & 642 \\
\hline 13 & Murayama Y. et al. & 2003 & $\begin{array}{l}\text { Guglielmi detachable coil embolization of cerebral aneurysms: } 11 \text { Years' } \\
\text { experience }\end{array}$ & Endovascular & 601 \\
\hline 14 & Lylyk P. et al. & 2009 & $\begin{array}{l}\text { Curative endovascular reconstruction of cerebral aneurysms with the } \\
\text { pipeline embolization device: The Buenos Aires experience }\end{array}$ & Endovascular & 561 \\
\hline 15 & Guglielmi G. et al. & 1992 & $\begin{array}{l}\text { Endovascular treatment of posterior circulation aneurysms by } \\
\text { electrothrombosis using electrically detachable coils }\end{array}$ & Endovascular & 495 \\
\hline 16 & Molyneux A.J. et al. & 2009 & $\begin{array}{l}\text { Risk of recurrent subarachnoid haemorrhage, death, or dependence and } \\
\text { standardised mortality ratios after clipping or coiling of an intracranial } \\
\text { aneurysm in the International Subarachnoid Aneurysm Trial (ISAT): long- } \\
\text { term follow-up }\end{array}$ & Surgical +Endovascular & 490 \\
\hline 17 & Suarez J.I. et al. & 2006 & Aneurysmal subarachnoid hemorrhage & Surgical + endovascular & 479 \\
\hline 18 & Zubillaga A.F. et al. & 1994 & $\begin{array}{l}\text { Endovascular occlusion of intracranial aneurysms with electrically } \\
\text { detachable coils: Correlation of aneurysm neck size and treatment results }\end{array}$ & Endovascular & 466 \\
\hline 19 & Roy D. et al. & 2001 & Endovascular treatment of unruptured aneurysms & Endovascular & 462 \\
\hline 20 & Brisman J.L. et al. & 2006 & Cerebral aneurysms & Surgical + endovascular & 448 \\
\hline 21 & Nelson P.K. et al. & 2011 & $\begin{array}{l}\text { The pipeline embolization device for the intracranial treatment of aneurysms } \\
\text { trial }\end{array}$ & Endovascular & 412 \\
\hline 22 & Solenski N.J. et al. & 1995 & $\begin{array}{l}\text { Medical complications of aneurysmal subarachnoid hemorrhage: A report of } \\
\text { the multicenter, cooperative aneurysm study }\end{array}$ & Medical & 411 \\
\hline 23 & Moret J. et al. & 1997 & $\begin{array}{l}\text { Reconstruction technique for wide neck intracranial aneurysms: Long-term } \\
\text { angiographic and clinical results }\end{array}$ & Endovascular & 409 \\
\hline 24 & Alberts M.J. et al. & 2005 & $\begin{array}{l}\text { Recommendations for comprehensive stroke centers: A consensus statement } \\
\text { from the brain attack coalition }\end{array}$ & Surgical + endovascular & 401 \\
\hline
\end{tabular}


In order to provide some indication of influence of the opensurgical versus endovascular literature in the recent past, we calculated the 10-year h-index of these two fields. In this case, the h-index is equal to a number, $h$, where a particular field has $h$ number of publications with at least $h$ number of citations. This was originally proposed by Hirsch as a metric to compare the research output of individual authors. ${ }^{9}$ In this case, we used all the surgical IA articles in the last 10 years (2008-2017) yielded by our search to calculate a field-specific h-index. We did the same for all the endovascular articles published in the last 10 years. We also found the most highly cited articles among our results and compiled a list of "citation classics" (articles that have been cited over 400 times) in order to help ascertain the most impactful topics over time. We surveyed their abstracts to classify their primary focus as either surgical, endovascular, medical, or a combination.

\section{Results}

The number of papers published varied with each procedure (Table 1). A search for all treatment of IAs yielded 21,255 publications between the years of 1938 and 2017. The annual number of publications on IA treatment was modest throughout most of the 20th century but then accelerated in the 1970s. The average annual number of publications was 95 in the 1970s, 150 in the 1980s, 330 in the 1990s, 636 in the 2000s, and 1077 in the 2010s. A peak of 1241 annual publications was reached in 2016.

Our search identified 24 articles with over 400 citations, which earned them the designation of citation classic (Table 2). Only four articles were exclusively surgical in nature while nine were exclusively on endovascular approaches. The remaining articles consisted of trials and reviews that focused on both endovascular and surgical approaches or medical treatment topics. The 10-year (2008-2017) h-index was 51 for open-surgical articles (51 surgical articles published in the last 10 years that received 51 or more citations) and 86 for endovascular articles (86 endovascular articles published in the last 10 years that have 86 or more citations).

\section{Surgical Approaches}

A generic search for surgical treatment of IA found 5956 articles. The first publication found was a 1947 article by Jefferson titled "Isolated oculomotor palsy caused by intracranial aneurysm," 10 which discussed proximal artery ligature and clipping as treatments for IA. There was very little growth in the number of annual publications around mid-century. This period of low activity was followed by steady growth beginning in the 1970s toward a peak of 299 publications in 2015. The number of annual publications on surgical approaches was maintained or declined slightly year-over-year from 2015-2017. Figure 1 shows a comparison of annual publications in surgical and endovascular topics over time, as returned by our searches.

A search for publications relating specifically to IA clipping found a similar pattern to the generic search for surgical articles. In total, 4204 publications were found spanning 1947-2017. The first publication in 1947 was the one described above.

We also searched for publications regarding EC-IC bypass and IC-IC bypass techniques yielding 23 and 16 publications, respectively. The first instance of EC-IC bypass in our search

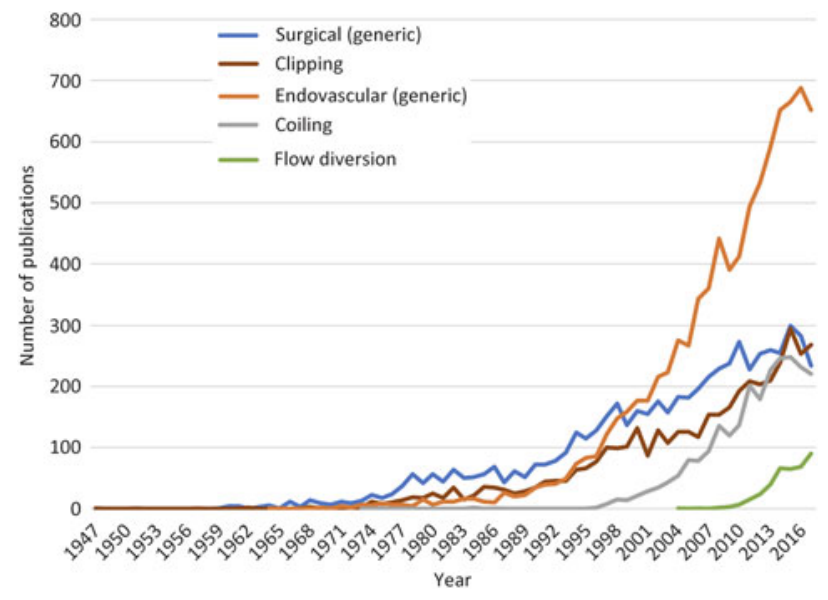

Figure 1: Annual counts of papers published on surgical and endovascular IA treatments until 2017. Data were derived from the Scopus database as described in methods.

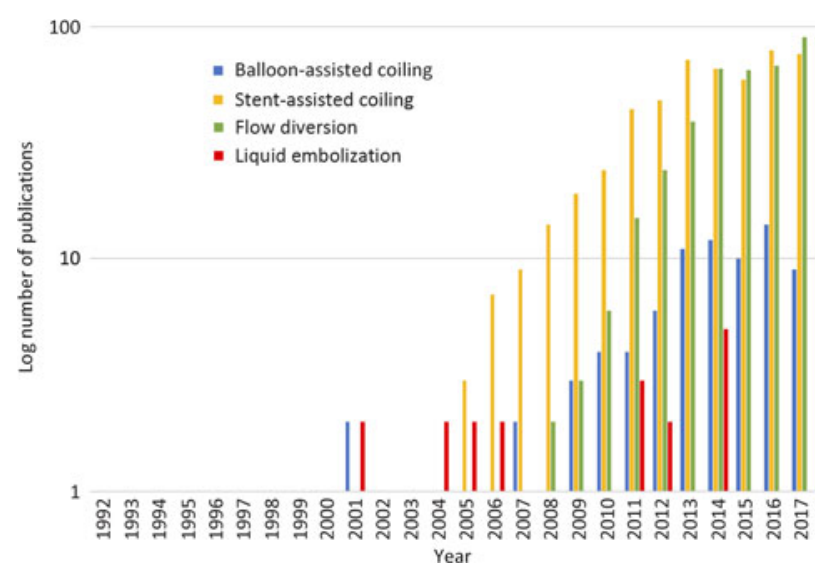

Figure 2: Annual counts of papers published on four different endovascular approaches for IA until 2017. Note the counts are displayed on a logarithmic scale. The four approaches are balloonassisted coiling, stent-assisted coiling, flow diversion, and liquid material embolization.

was titled "The role of EC-IC in the treatment of giant intracranial aneurysms" by Speztler et al., in $1980 .{ }^{11}$ Most of the publications for EC-IC bypass, however, occurred in the 2010s. The first instance of IC-IC bypass was by Streefkerk et al., in $2004 .^{12}$ Similar to EC-IC bypass, most of the activity occurred in the 2010s.

\section{Endovascular Approaches}

A generic search for endovascular treatment of IA found 8602 articles spanning 1964-2017. The first article was in 1964 by Brizzi. It was an Italian article with a translated title: " 2 cases of congenital arteriovenous aneurysm of the brain treated by means of embolization with lipiodol-wax.". ${ }^{13}$ However, we were unable to locate a copy or abstract of this paper to verify that it was truly an endovascular approach and suspect that it was not. The timeline of endovascular approaches shows minimal growth between the initial publication in 1964 and the 1980s. It was only in the 1990s-2000s that substantial growth was seen. The maximum number of 688 publications was reached in 2016 and 


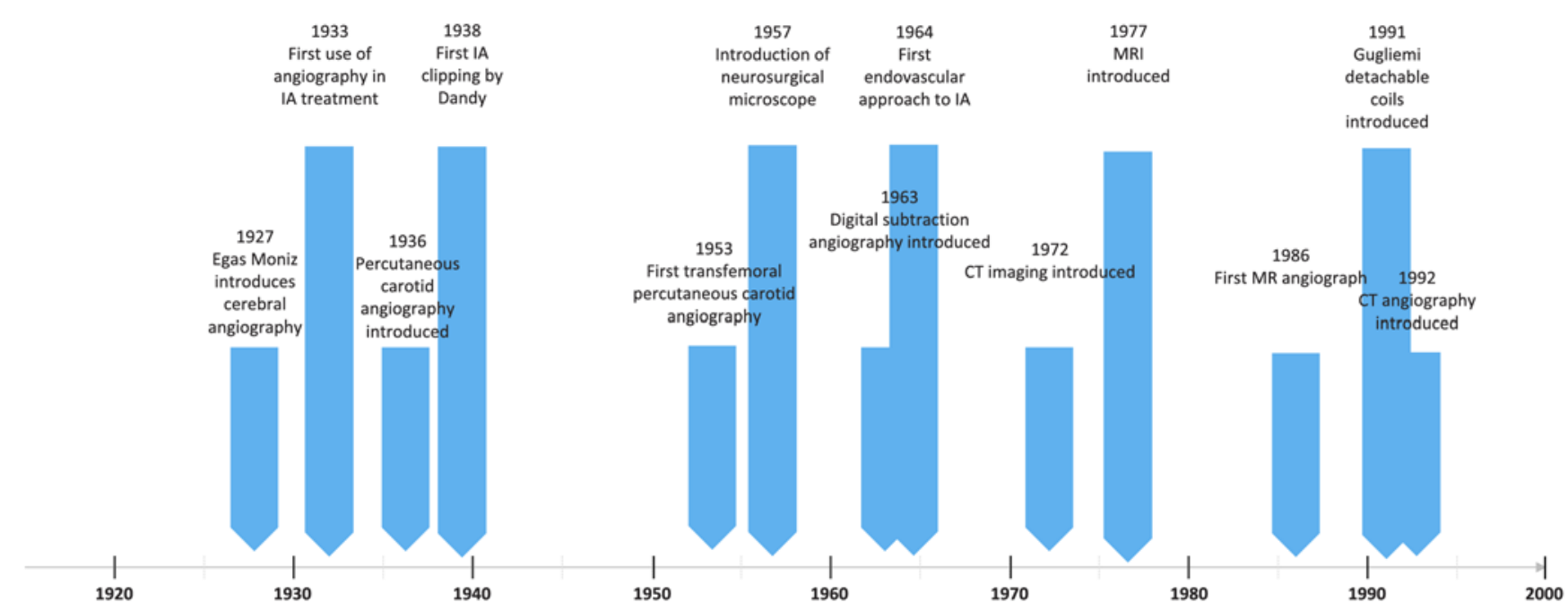

Figure 3: Timeline showing milestones and major innovations in treatment of IA.

has since leveled off. A particular point of interest is 1999, which was the year where the number of endovascular publications surpassed surgical ones and continued to remain more numerous ever since.

Our search for publications relating to endovascular coiling of IAs found 5436 results beginning in 1985. This 1985 article was a case series by Braun et al. ${ }^{14}$ describing the use of Gianturco coils for internal carotid aneurysms. The time course of annual coiling publications is similar to that of the generic endovascular search.

We also examined several other emerging endovascular techniques such as balloon-assisted coiling, stent-assisted coiling, flow diversion, and liquid embolization. The time course of publications for these procedures is shown in Figure 2. Of note is stent-assisted coiling which had the largest body of literature of all these techniques with 522 publications. Both stent-assisted coiling and flow diversion demonstrate steep upward trends although still only make up a small proportion of the total endovascular literature. Balloon-assisted coiling has also seen an upward trend although not to the same consistency and magnitude. The number of publications on liquid embolization has been low with sporadic activity over the past two decades with no obvious trend.

\section{Discussion}

\section{Surgical IA Publications}

Surgery for IAs has been around for more than 100 years. Some early approaches included proximal carotid artery ligation by Horsley in the late $1800 \mathrm{~s}^{15}$ and Dott's muscle tissue wrapping of IAs in the early 1930s. ${ }^{16}$ Interestingly, some of these early articles escaped detection in our searches despite containing several keywords in their titles.

The earliest articles returned by our search were published in the 1930s onward, coinciding with the introduction of IA clipping surgery. The first record of IA clipping came from Dandy, who in 1938 published an account of using Cushing-McKenzie silver clip to treat an internal carotid artery aneurysm. ${ }^{17}$ According to our search results, activity in the IA literature remained low early on, despite the introduction of clipping. This lack of activity was perhaps a consequence of high mortality and morbidity associated with surgical treatment of IAs during this time. ${ }^{18}$ There was a notable uptick in the number of publications around the 1960s, and this coincided with the introduction of the neurosurgical microscope. Under the microscope, aneurysm surgery was able to see a dramatic improvement in outcomes. ${ }^{19}$ This uptick in publications is also likely associated with improvements in clip design by Drake, Sugita, and Yasargil in the 1960s and $1970 \mathrm{~s} .{ }^{20}$ It is clear from our results that clipping is the dominant surgical approach for IA as it produced the largest proportion of surgical publications. We also examined other surgical approaches such as EC-IC and IC-IC bypass techniques which made a contribution, albeit small, to the tally of surgical articles in the 2000s.

\section{Endovascular IA Publications}

According to our searches, endovascular approaches to IA treatment emerged largely in the 1990s, despite some early outliers. The first published account of the suggestion of using an endovascular approach for IA came in 1964 by Luessenhop et al., ${ }^{21}$ who were early explorers in cerebral artery catheterization. Publications on endovascular approach began to emerge in the 1970s and 1980s as catheter design and endovascular techniques were improved. Still, activity in the field remained low perhaps because surgical clipping was now well established and endovascular approaches were still prone to high rates of complications. ${ }^{22}$ The field only really started to accelerate in the late 1990s after the introduction of detachable coils for embolization by Guglielmi in $1991{ }^{7}$ This new technique was able to avoid many of the shortcomings of the older balloon-based approaches. This period of rapid growth was also likely facilitated by MR angiography in $1986^{23}$ and CT angiography in $1992 .{ }^{24}$ Coiling has become the dominant endovascular approach. Publications on balloon- and stent-assisted coiling both had similar patterns to coiling, showing rapid growth during the 2000s, but their overall volume was much lower. From a bibliometric perspective, flow diversion appears to an up-and-coming technique, with most of its growth occurring in the last 5 years. Conversely, annual publications in coiling have plateaued, indicating that the field has matured. 


\section{The Current and Future Landscape of IA Treatment}

It comes as no surprise that there has been a paradigm shift in the IA field. Historically, surgical clipping has been the dominant approach to treatment (Figure 3); however over the past three decades, our results indicate that endovascular approaches have begun to garner more interest. Two of the top three most cited articles in IA treatment, the International Subarachnoid Aneurysm Trial (ISAT) in $2002^{25}$ and the International Study of Unruptured Intracranial Aneurysms (ISUIA) in $2003,{ }^{26}$ compared these two approaches, signaling a field-wide debate. Despite its rising popularity, coiling still faces its own barriers such as having a reported greater risk of rebleeding compared to clipping. ${ }^{27}$ In addition, in certain cases, for example, those associated with large mass effect from a hematoma secondary to acute rupture or individuals where aneurysm anatomy and the ratio of the neck to the fundus are unfavorable, open procedures with clipping may be preferred. Despite these limitations, endovascular publications have surpassed open-surgical ones.

While the advantages of endovascular approaches over open surgery could be one source of the increased publications in the endovascular literature, there are other factors at play. For example, the number of incidental unruptured asymptomatic aneurysms that are being detected has increased over time due to improvements and increased accessibility to imaging technology. ${ }^{28}$ These aneurysms which previously would have not been dealt with surgically are perhaps now being treated with endovascular methods, fueling more publications. Another source of increased publications in the endovascular literature could come from the fact that both neurosurgeons and interventional radiologists could be publishing papers on endovascular topics, causing a larger author pool. Finally, part of the dramatic increase seen in publications could also be due to a general trend toward more publishing over time.

Since the h-index relies on both quantity (the number of publications) and quality (the number of highly cited publications), ${ }^{29}$ we used this measure as a broad indicator of academic interest and impact. The h-index has typically been used as an indicator of impact, especially to rank individual authors, journals, or institutions, but it also has been proposed as an indicator of "hottopics" in a particular field. ${ }^{30}$ In this case, we used it to compare surgical papers and endovascular papers. A higher h-index, as is the case for endovascular articles, indicates a greater number of highly cited articles and therefore a greater amount of high-impact activity in this topic. ${ }^{30}$ The increased 10 -year h-index of the endovascular versus surgical literature supports the notion that the IA field is transitioning away from surgical approaches in the recent past.

\section{Limitations}

The purpose of this study was to appraise the trends of publications on IA treatment over time in the context of technological innovations. Importantly, this was not a systematic review which would have necessitated a thorough review of individual articles. Our bibliometric approach is practical, but not without limitations. The most significant problem encountered was false positives and false negatives returned by our searches. We noted several important articles that did not appear in our search results. This can be attributed to a variety of factors including the lack of journal coverage in the Scopus database and problems with the search terms we used. If articles used synonyms or alternative phrasing to the terms used in our searches, they would have been missed. Conversely, we found many false positives within our search results due to common terminology across unrelated fields. Many of these false-positive articles were related to aneurysm, but not necessarily cerebral aneurysm. In designing search queries, there must be a fine balance between including relevant key words while not being too broad. Another issue we encountered was slight discrepancies in articles returned by different databases. For example, some articles were found on PubMed but not Scopus. We recognize that other databases are available but chose to use Scopus due to its robust citation information and ease of use for exporting search results into Excel spreadsheets to facilitate analysis. We feel that differences across the major publication databases are relatively minor and that they would have yielded largely similar results.

We used the number of publications in a topic as proxy for academic interest in a particular procedure over time. This is an inherently crude approach, although it does provide a practical and reproducible measure and has been used before for a similar investigation. ${ }^{31}$ Still, it does fail to take into consideration a variety of biases, such as centers that perform surgeries but do not publish results, the time lag between surgery and publication of results, as well as socioeconomic factors, e.g. the favoring of procedures based on local cost and accessibility. To circumvent some of these limitations, a future study could conduct direct counts of the number of procedures being done with each technique as obtained by surveying national databases. Our analysis of the 10-year $\mathrm{h}$-index of endovascular versus surgical publications is also prone to these biases. Importantly, the h-index is highly discipline specific. ${ }^{29}$ Perhaps having both neurosurgeons and interventional radiologist contributing to the endovascular literature versus neurosurgeons only in the surgical literature is skewing the results. Limitations aside, the h-index provides a simple and reproducible metric for comparison that is within the scope of our investigation.

\section{Conclusion}

The state of IA treatment is constantly evolving. Surgical approaches have benefited from technical improvements over time. The advent of new minimally invasive endovascular approaches in the 1990s was a major turning point in the IA field, bringing the once definitive role of clipping into question. Publications on endovascular techniques experienced a more rapid rise to prominence and have now surpassed the number of surgical articles.

\section{ACKNOWLEDGEMENTS}

We would like to acknowledge the Royal College of Surgeons in Ireland and the Keenan Summer Student Research Program for their support of this research.

\section{Disclosures}

The authors have no conflicts of interest to disclose.

\section{Statement of Authorship}

Conception and design: CS Lozano, J Spears. Acquisition of data: CS Lozano. Analysis and Interpretation of data: CS Lozano, J Spears. Drafting of article: CS Lozano. Critical revision of article: AM Lozano, J Spears. Review of submitted version of article: all authors. Study supervision: J Spears. 


\section{REFERENCES}

1. Al-Shatoury HA, Raja AI, Ausman JI. Timeline: pioneers in cerebral aneurysms. Surg Neurol. 2000;54:465-70.

2. Cooper A. A case of aneurism of the carotid artery. Med Chir Trans. $1809 ; 1: 1-12.1$

3. Cooper A. Second case of carotid aneurism. Med Chir Trans. 1809;1:224-35.

4. Schorstein J. Carotid ligation in saccular intracranial aneurysms. $\mathrm{Br}$ J Surg. 1940;28:50-70.

5. Lai LT, O'Neill AH. History, evolution, and continuing innovations of intracranial aneurysm surgery. World Neurosurg. 2017; 102:673-81.

6. Molyneux AJ, Kerr RS, Yu L-M, et al. International subarachnoid aneurysm trial (ISAT) of neurosurgical clipping versus endovascular coiling in 2143 patients with ruptured intracranial aneurysms: a randomised comparison of effects on survival, dependency, seizures, rebleeding, subgroups, and aneurysm occlusion. Lancet. 2005;366:809-17.

7. Guglielmi G, Viñuela F, Sepetka I, Macellari V. Electrothrombosis of saccular aneurysms via endovascular approach. J Neurosurg. 1991;75:1-7.

8. Hui FK, Fiorella D, Masaryk TJ, Rasmussen PA, Dion JE. A history of detachable coils: 1987-2012. J Neurointerv Surg. 2014;6: 134-8.

9. Hirsch JE. An index to quantify an individual's scientific research output. Proc Natl Acad Sci USA. 2005;102:16569-72.

10. Jefferson $G$. Isolated oculomotor palsy caused by intracranial aneurysm. Proc R Soc Med. 1947;40:419-32.

11. Spetzler RF, Roski RA, Schuster H, Takaoka Y. The role of EC-IC in the treatment of giant intracranial aneurysms. Neurol Res. 1980;2:345-59.

12. Streefkerk HJN, Wolfs JFC, Sorteberg W, Sorteberg AG, Tulleken CAF. The ELANA technique: constructing a high flow bypass using a non-occlusive anastomosis on the ICA and a conventional anastomosis on the SCA in the treatment of a fusiform giant basilar trunk aneurysm. Acta Neurochir (Wien). 2004;146:1009-19.

13. Brizzi RE. 2 cases of congenital arteriovenous aneurysm of the brain treated by means of embolization with lipiodol-wax. Riv Neurobiol. 1964; 10:3-16.

14. Braun IF, Hoffman JC, Casarella WJ, Davis PC. Use of coils for transcatheter carotid occlusion. AJNR Am J Neuroradiol. 1985; 6:953-6.
15. Drake CG. Earlier times in aneurysm surgery. Clin Neurosurg. 1985;32:41-50.

16. Moniz E. Cerebral angiography with thorotrast. Arch Neurol Psychiatry. 1933;29:1318.

17. Dandy WE. Intracranial aneurysm of the internal carotid artery: cured by operation. Ann Surg. 1938;107:654-9.

18. Norlén G, Olivecrona $\mathrm{H}$. The treatment of aneurysms of the circle of Willis. J Neurosurg. 1953;10:404-15.

19. Krayenbühl HA, Yaşargil MG, Flamm ES, Tew Jr JM. Microsurgical treatment of intracranial saccular aneurysms. J Neurosurg. 1972;37:678-86.

20. Dujovny M, Agner C, Ibe O, Perlin A. Self-closing aneurysm clip: a historical review. Neurol Res. 2010;32:1011-20.

21. Luessenhop AJ, Velasquez AC. Observations on the tolerance of the intracranial arteries to catheterization. J Neurosurg. 1964;21:85-91.

22. Guglielmi G. History of endovascular endosaccular occlusion of brain aneurysms: 1965-1990. Interv Neuroradiol. 2007;13:217-24.

23. Dumoulin CL, Hart HR. Magnetic resonance angiography. Radiology. 1986;161:717-20.

24. Napel S, Marks MP, Rubin GD, et al. CT angiography with spiral CT and maximum intensity projection. Radiology. 1992;185: 607-10.

25. Molyneux A, Kerr R, Stratton I, et al. International subarachnoid aneurysm trial (ISAT) of neurosurgical clipping versus endovascular coiling in 2143 patients with ruptured intracranial aneurysms: a randomised trial. Lancet (London, England). 2002; 360:1267-74.

26. Wiebers DO, Whisnant JP, Huston J, et al. Unruptured intracranial aneurysms: natural history, clinical outcome, and risks of surgical and endovascular treatment. Lancet (London, England). 2003; 362:103-10.

27. Li H, Pan R, Wang H, et al. Clipping versus coiling for ruptured intracranial aneurysms: a systematic review and meta-analysis. Stroke. 2013;44:29-37.

28. Tummala RP, Başkaya MK, Heros RC. Contemporary management of incidental intracranial aneurysms. Neurosurg Focus. 2005;18:e9.

29. Costas R, Bordons M. The h-index: advantages, limitations and its relation with other bibliometric indicators at the micro level. J Informetr. 2007;1:193-203.

30. Bornmann L, Daniel H-D. What do we know about the $\mathrm{h}$ index? J Am Soc Inf Sci Technol. 2007;58:1381-5.

31. Lozano CS, Tam J, Lozano AM. The changing landscape of surgery for Parkinson's Disease. Mov Disord. 2018;33:36-47. 